\title{
A change in perspective
}

\author{
Jennifer Pritchard, BSc, MD
}

In July 2010, Pakistan was hit with massive flooding, the worst the country had seen in 80 years. The natural disaster left devastating effects: an estimated 20 million people were affected, ${ }^{1}$ with up to 1,500 deaths being reported, ${ }^{2}$ and left 11 million people homeless. ${ }^{3}$ Health care was an immediate concern, and with over 200 hospitals and clinics destroyed, there was great need for help.

I had the opportunity to travel to Pakistan to provide medical relief to some of the internally displaced persons. These people had been uprooted from their homes and were living with thousands of others in camps scattered around the country. At the outset, I looked at this as an opportunity to gain some clinical experience overseas while putting some of my skills to use to help those in need, completely naive to the complexity of humanitarian work and the effect it would have on me.

I was aware of the controversy regarding humanitarian work and its unintended impact on developing countries. ${ }^{4,5}$ Yet with such a huge need, despite my uncertainty and, at times, moral distress, I decided to go. I did my best to keep in mind these important issues, thinking ahead about the effect our team could have (both positive and negative) on these people. The experience itself was one I could never have imagined. The magnitude of health care problems on the ground, combined with constant concerns over the impact we were having, and of corruption and an overwhelming sense of distrust, made it an experience like no other. What I did not expect were the difficulties that I would face returning home.

Seeing such poverty and despair creates a great sense of guilt for all that one has as the result of living in a first world country. My inner struggles were one issue, but my biggest challenge was my change in attitude toward my patients. The first patient I saw once back at work in Canada was an older gentleman, a poorly controlled diabetic who seemed to be vying for the world record in the number of jelly beans consumed by one patient during a hospital stay. Predictably, he was in hospital for diabetes-related complications and spent his days lying in bed, complaining about the "system" and the "care" he was receiving, pausing only to reach for another jelly bean. His sense of entitlement and lack of personal accountability were overbearing. It took all of my willpower to refrain from lashing out and telling him how lucky he was to have access to good care and how perhaps he would not be in this situation if he took better care of himself. I had to leave his room before losing the battle. Did he not know there were people who did not have clean water, much less access to any type of medical care? Was he aware of the thousands of children, all with orangetinted hair owing to their severe malnutrition, who had never seen a physician or any other health care professional? I wished I could tell him what I really thought, but the sensible part of my brain kicked in, and I realized that this was not the time or place to have it out with this patient, who probably would not hear a word I said. I somehow managed to gracefully exit his room and kept telling myself, "It's not him; it's you that has changed." Warned of culture shock when returning home, I had remained skeptical until this moment. How would I be able to see past this? Would I only see people who were complaining and unhappy with all that they had?

Thinking back to the people I met in Pakistan, I remembered more than just the pain and suffering. I remembered people who, despite poverty, malnutrition, and the unfairness of the flood, were still smiling and

From the Department of Emergency Medicine, University of Alberta, Edmonton, AB.

Correspondence to: Dr. Jennifer Pritchard, Department of Emergency Medicine; 1G1.WMC, 8440-112th Street, Edmonton, AB T6G 2C7; jep2@ ualberta.ca.

This article has been peer reviewed. 
laughing. Their appreciation was reflected on their faces and silently expressed by the simple act of grasping your hand. After a few shifts back home in the emergency department, I quickly began to see some of these same people. If you look, there are patients who are grateful for care, for reassurance, for having you take away their pain, and even for the extra 5 minutes you spend with them, listening to their story.

It can be challenging in medicine not to be overcome with all the tragic events and unrealistic expectations held by some of our patients. It is easy to become jaded and cynical and see all of your patients through this tainted lens or fail to see the ones who are kind and appreciative. The media tells us that we are failing, that wait times are too long and patients are dying in the waiting rooms. Although there is truth to these criticisms, there is also a lot of good happening each and every day that we fail to notice.

We live in a world that tends to focus on the bad and the ugly because it makes headline news. But where is the good? When was the last time you heard a story from a patient, coworker, family member, or friend about someone who went out of his or her way, exceeded expectations, or simply did a great job? It becomes easy to overlook the success stories and perpetuate the sense of failure, but there is goodness happening every day. We just need to see it.

My experience in Pakistan gave me a glimpse at the disparity that exists in health care around the world. It forced me to see all that I have in front of me and to appreciate it every day-to recognize how fortunate I am to have been so lucky in the lottery that is life, to have been born in a country with so much opportunity and know that I have access to the things I need. Our medical system is not perfect, but at least we have a system that provides for everyone, regardless of how much money they have. Today, I try to look more closely for those people who are appreciative of what they have and have reasonable expectations of being heard, of kindness, and of mutual respect. It helps chip away at any cynicism I have accrued during my short time in medicine. We should all take the time to appreciate what we have while making things even better.

Competing interests: None declared.

Keywords: changing perspective, Pakistan floods

\section{REFERENCES}

1. UN Dispatch - United Nations News \& Commentary Global News Forum. Pakistan floods facts and figures. 2010 Aug. Available at: http://www.undispatch.com/pakistan-floodsfacts-and-figures (accessed November 2010).

2. CBC News. Pakistan floods leave thousands stranded. 2010 Aug. Available at: http://www.cbc.ca/world/story/2010/08/25/pakistanus-flood-relief.html (accessed November 2010).

3. AlertNet. Pakistan floods 2010. Available at: http://www.trust. org/alertnet/crisis-centre/crisis/pakistan-floods-2010 (accessed March 8, 2012).

4. Jobe K. Disaster relief in post earthquake Haiti: unintended consequences of humanitarian volunteerism. Travel Med Infect Dis 2011;9:1-5, doi:10.1016/j.tmaid.2010.10.006

5. Bezruchka S. Medical tourism as medical harm to the third world: why? for whom? Wilderness Environ Med 2000;11:77-8, doi:10.1580/1080-6032(2000)011[0077:MTAMHT]2.3.CO;2. 